\title{
Submesoscale Dynamics in the Northern Gulf of Mexico. Part II: Temperature-Salinity Relations and Cross-Shelf Transport Processes $\mathscr{\mathscr { O }}$
}

\author{
Roy Barkan, James C. McWilliams, And M. Jeroen Molemaker \\ Department of Atmospheric and Oceanic Sciences, University of California, Los Angeles, Los Angeles, \\ California \\ JUN CHOI \\ School of Earth and Atmospheric Sciences, Georgia Institute of Technology, Atlanta, Georgia \\ KAUSHIK SRINIVASAN AND ALEXANDER F. SHCHEPETKIN \\ Department of Atmospheric and Oceanic Sciences, University of California, Los Angeles, Los Angeles, \\ California \\ ANNALISA BRACCO \\ School of Earth and Atmospheric Sciences, Georgia Institute of Technology, Atlanta, Georgia
}

(Manuscript received 27 February 2017, in final form 14 July 2017)

\begin{abstract}
This paper, the second of three, investigates submesoscale dynamics in the northern Gulf of Mexico under the influence of the Mississippi-Atchafalaya River system, using numerical simulations at 500-m horizontal resolution with climatological atmospheric forcing. The Turner angle $\mathrm{Tu}$, a measure of the relative effect of temperature and salinity on density, is examined with respect to submesoscale current generation in runs with and without riverine forcing. Surface Tu probability density functions in solutions including rivers show a temperature-dominated signal offshore, associated with Loop Current water, and a nearshore salinity-dominated signal, associated with fresh river water, without a clear compensating signal, as often found instead in the ocean's mixed layer. The corresponding probability distribution functions in the absence of rivers differ, illustrating the key role played by the freshwater output in determining temperature-salinity distributions in the northern Gulf of Mexico during both winter and summer. A quantity referred to as temperature-salinity covariance is proposed to determine what fraction of the available potential energy that is released during the generation of submesoscale circulations leads to the destruction of density gradients while leaving spice gradients untouched, thereby leading to compensation. It is shown that the fresh river fronts to the east of the Bird's Foot can evolve toward compensation in concert with a gradual release of available potential energy. It is further demonstrated that, during winter, the cross-shelf freshwater transport mechanism to the west of the Bird's Foot is well approximated by a diffusive process, whereas to the east is better represented by a ballistic process associated with the Mississippi water that converges in a jetlike pattern.
\end{abstract}

\section{Introduction}

In Barkan et al. (2017, hereinafter Part I), we used a suite of realistic submesoscale-resolving numerical simulations to characterize surface submesoscale statistics and spatial patterns in the northern Gulf of

Supplemental information related to this paper is available at the Journals Online website: https://doi.org/ JPO-D-17-0040.s1.

Corresponding author: Roy Barkan, rbarkan@atmos.ucla.edu
Mexico (GoM) during winter and summer, with a particular emphasis on understanding the role played by the Mississippi-Atchafalaya River system (hereinafter rivers). The northern GoM has recently received much attention because of the 2010 Deepwater Horizon oil spill that took place in the De Soto Canyon. Following this catastrophic event, two major experiments attempted to quantify and understand the flow dynamics that determined the transport and dispersion mechanisms of contaminants in this region. The Grand Lagrangian Deployment (GLAD) 
experiment took place in the summer of 2012 and demonstrated, through the analysis of a large number of drifter trajectories, that submesoscale currents dominate the dispersion statistics in the northern GoM. More recently, in the winter of 2016, the Lagrangian Submesoscale Experiment (LASER) aimed at exploring a different season, focusing on both mean dispersion statistics and individual submesoscale features.

In Part I, the comparison between two statistically equilibrated solution sets with (With-River) and without (No-River) river forcing demonstrated that, on average, the rivers tend to suppress submesoscale currents in winter and enhance them in summer and that such tendencies increase with resolution. The suppression is most prominent wherever fresh river water is more abundant and outside of the mesoscale Loop Current eddies. This is the case in winter east of the Mississippi River delta or Bird's Foot. In summer, the enhancement is stronger than the suppression during winter and quantifiable throughout most of the computational domain. These river effects are rationalized in terms of scaling arguments that relate submesoscale current magnitudes to the surface boundary layer depth and lateral buoyancy gradients. Riverine outflow enhances submesoscale currents by increasing lateral buoyancy gradients but suppresses them by decreasing boundary layer depth.

In this paper, we review the model setup (section 2) and analyze temperature-salinity relations with an emphasis on the role of submesoscale currents (section 3). In section 4 , we investigate the cross-shelf transport mechanisms of fresh river water west of the Bird's Foot and in the river jet region east of the Bird's Foot. Finally, in section 5, we provide a summary of our findings.

\section{Model setup}

The numerical simulations are carried out with the Regional Oceanic Modeling System (ROMS; Shchepetkin and McWilliams 2005) using a nonlinear equation of state (Shchepetkin and McWilliams 2011) and a one-way nesting procedure (Mason et al. 2010) and focusing on solutions in the northern GoM region with an approximately $500-\mathrm{m}$, nearly isotropic, horizontal resolution. The vertical stretching parameters (see Table 1 in Part I) are designed to have vertical resolution of approximately $5-7 \mathrm{~m}$ in the near-surface boundary layer offshore and much finer nearshore. The atmospheric forcing is climatological with a QuikSCAT-based daily product of scatterometer wind stresses (Risien and Chelton 2008), CORE (Large and Yeager 2009) monthly heat flux atmospheric forcing, and HOAPS (Andersson et al. 2010) monthly freshwater atmospheric forcing. No tidal forcing is used, and a daily river forcing is applied based on daily river volume flux data from the USGS (http://waterdata.usgs.gov/nwis/rt) for the year 2010. The analysis is carried out based on 2 years of equilibrated solution sets for winter (January, February, March) and summer (June, July, August) months, with (With-River) and without (No-River) riverine forcing, using a twice-per-day output frequency. Additional information about the numerical setup is provided in Part I.

For the Lagrangian tracer simulations in this work, the advection is performed offline using the ROMS hourly averaged horizontal velocity field for the month of February and the larval transport Lagrangian model (LTRANS), version $2 b$ (North et al. 2011). We consider multiple releases of 5019 particles seeded uniformly in circular clusters of $40-\mathrm{km}$ diameter [more details available in Choi et al. (2017, hereinafter Part III)].

\section{Temperature-salinity relations}

The analysis of the numerical simulations at 500-m horizontal resolutions presented in Part I and the observations of extremely sharp surface temperature gradients made by M. J. Molemaker et al. (2017, unpublished manuscript) motivate us to investigate the temperaturesalinity $(T-S)$ relations in the northern GoM.

In oceanic observations, $T-S$ relations are often analyzed in terms of the density ratio

$$
\mathcal{R}=\frac{\alpha \Delta T}{\beta \Delta S}
$$

or Turner angle

$$
\mathrm{Tu}=\arctan (\mathcal{R}),
$$

where $\alpha$ and $\beta$ are the expansion and contraction coefficients of potential temperature $T$ and salinity $S$, respectively (Schmitt 1981). The $\Delta T$ and $\Delta S$ are the temperature and salinity differences over a spatial interval that in field measurements is assumed to be in the direction of the towed measuring instrument (Ferrari and Rudnick 2000). ${ }^{1}$ Positive $\mathcal{R}$ values are referred to as

\footnotetext{
${ }^{1}$ This definition of the Turner angle is different from the original definition (Ruddick 1983), which is based on the ratio of vertical derivatives of temperature and salinity.
} 


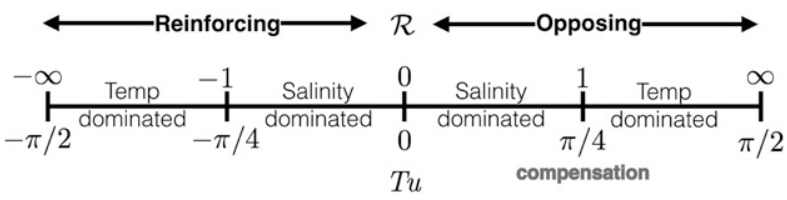

FIG. 1. A schematic illustrating the ranges spanned by the density ratio $\mathcal{R}[(1)]$ and Turner angle $\mathrm{Tu}[(2)]$ as well as the opposing, reinforcing, and compensation regimes (see section 3 for detail).

opposing because temperature and salinity gradients have an opposing effect on density gradients, and negative $\mathcal{R}$ values are referred to as reinforcing (Fig. 1). Values in the range $(-1<\mathcal{R}<1)$ are salinity dominated, and values in the range $1<|\mathcal{R}|<\infty$ are temperature dominated. Compensation is defined for regions where $\mathcal{R}=1$ and is associated with perfectly opposing temperature and salinity gradients. Equivalently, equipartition is defined for regions where $\mathcal{R}=-1$ and is associated with flows that have equal and reinforcing contributions of temperature and salinity to density gradients. Using the Turner angle is preferable because it replaces the infinite scale of $\mathcal{R}$ with a finite one composed between $-\pi / 2$ to $\pi / 2$, values associated with $\Delta S=0$ are well defined, and the salinity- and temperature-dominated regions occupy the same space on the Tu scale: $(0<|\mathcal{R}|<1) \rightarrow(0<|\mathrm{Tu}|<\pi / 4)$ and $(1<$ $|\mathcal{R}|<\infty) \rightarrow(\pi / 4<|\mathrm{Tu}|<\pi / 2)$. When $\mathrm{Tu} \rightarrow \pm \pi / 2$ or $\mathrm{Tu} \rightarrow 0$, the flow is temperature dominated or salinity dominated, and the classification between opposing and reinforcing is moot.

Ferrari and Rudnick (2000) and Rudnick and Martin (2002) have shown that typical $\mathcal{R}$ values in the oceanic mixed layer are close to one ( $\mathrm{Tu}=+\pi / 4)$. This is often explained by the following simple dynamical argument: the external forcing and entrainment of thermocline waters drive lateral temperature and salinity gradients in the mixed layer, the available potential energy (APE) associated with the lateral buoyancy gradients that correspond to these temperature and salinity gradients is released, isopycnals are slumped, and the subsequent mixing removes any horizontal density gradients while leaving behind compensated salinity and temperature gradients that do not affect density. In this view, compensation is often seen as a proxy for submesoscale generation in the mixed layer. Local forcing scenarios, however, could have a substantial effect on the Turner angle [see Figs. 7 and 9 in Rudnick and Martin (2002)], driving it away from $\pi / 4$. Furthermore, locations with weak density gradients may have $\Delta T$ and $\Delta S$ approaching zero in a such a way that $\mathcal{R} \rightarrow 1$. In those places, the explanation discussed above is misleading.

It is instructive to relate $\mathcal{R}[(1)]$ to the ratio of the lateral (denoted by subscript $h$ ) density gradient $\nabla_{h} \rho=\rho_{0}\left(\alpha \nabla_{h} T-\beta \nabla_{h} S\right)$ to the lateral spice gradient $\nabla_{h} \gamma=\rho_{0}\left(\alpha \nabla_{h} T+\beta \nabla_{h} S\right)$, namely,

$$
\begin{gathered}
\frac{\nabla_{h} \rho \cdot \nabla_{h} \rho}{\nabla_{h} \gamma \cdot \nabla_{h} \gamma}=\frac{\left(1-\mathcal{C}_{T S}\right)}{\left(1+\mathcal{C}_{T S}\right)}, \\
=\frac{\left(\mathcal{R}_{x}-1\right)^{2}}{\left(\mathcal{R}_{x}+1\right)^{2}}\left[\frac{\left(\beta \partial_{x} S\right)^{2}+\left(\beta \partial_{y} S\right)^{2} \frac{\left(\mathcal{R}_{y}-1\right)^{2}}{\left(\mathcal{R}_{x}-1\right)^{2}}}{\left(\beta \partial_{x} S\right)^{2}+\left(\beta \partial_{y} S\right)^{2} \frac{\left(\mathcal{R}_{y}+1\right)^{2}}{\left(\mathcal{R}_{x}+1\right)^{2}}}\right] .
\end{gathered}
$$

The first expression in (3) illustrates that the ratio of the density gradient squared to the spice gradient squared depends on the sign and magnitude of the covariance

$$
\mathcal{C}_{T S}=\frac{2 \alpha \beta \nabla_{h} T \cdot \nabla_{h} S}{\alpha^{2} \nabla_{h} T^{2}+\beta^{2} \nabla_{h} S^{2}}
$$

which is coordinate invariant and bounded between -1 and +1 . If $\mathrm{C}_{T S} \rightarrow+1$, the magnitude of density gradients is much smaller than that of spice gradients, and the flow is compensated. Conversely, if $\mathrm{C}_{T S} \rightarrow-1$, the opposite is true and the flow is equipartitioned. Finally, if $\mathrm{C}_{T S} \rightarrow 0$, the magnitudes of density and spice gradients are comparable, and the flow is neither opposing nor reinforcing. An exception to this interpretation is a situation where $\nabla_{h} T$ and $\nabla_{h} S$ approach zero in such a way that $\mathrm{C}_{T S}$ approaches one. In this case, interpreting $\mathrm{C}_{T S}$ as a measure of compensation is misleading. This subtle point is illustrated in Figs. 5 and 6 of the subsection below.

The second expression in (3) highlights the relation of $\left|\nabla_{h} \rho\right|^{2} /\left|\nabla_{h} \gamma\right|^{2}$ to the zonal and meridional density ratios (or Turner angles):

$$
\begin{aligned}
\mathcal{R}_{x} & =\frac{\alpha \partial T / \partial x}{\beta \partial S / \partial x} \quad \text { and } \quad \mathcal{R}_{y}=\frac{\alpha \partial T / \partial y}{\beta \partial S / \partial y}, \\
\mathrm{Tu}_{x} & =\arctan \left(\mathcal{R}_{x}\right) \quad \text { and } \quad \operatorname{Tu}_{y}=\arctan \left(\mathcal{R}_{y}\right),
\end{aligned}
$$

which, in the limit that $\mathcal{R}$, is (statistically) independent of direction such that $\mathcal{R}_{x} \approx \mathcal{R}_{y} \approx \mathcal{R}$ becomes

$$
\frac{\nabla_{h} \rho \cdot \nabla_{h} \rho}{\nabla_{h} \gamma \cdot \nabla_{h} \gamma} \approx \frac{(\mathcal{R}-1)^{2}}{(\mathcal{R}+1)^{2}} .
$$

This suggests the following alternative explanation to the observed $\mathcal{R} \approx 1$ values in the mixed layer: if the statistically steady dynamics in the upper ocean is assumed to be nearly balanced (geostrophically or in a more general sense), then energy spectra of density gradients are expected to be steeper than spice gradients (Smith and Ferrari 2009) because the latter is a passive scalar. Consequently, spice gradient variance is presumed to be larger than density gradient variance, particularly at smaller scales, and following $(6), \mathcal{R} \rightarrow 1$. In general, however, $\mathcal{R}$ is independent of direction if and 

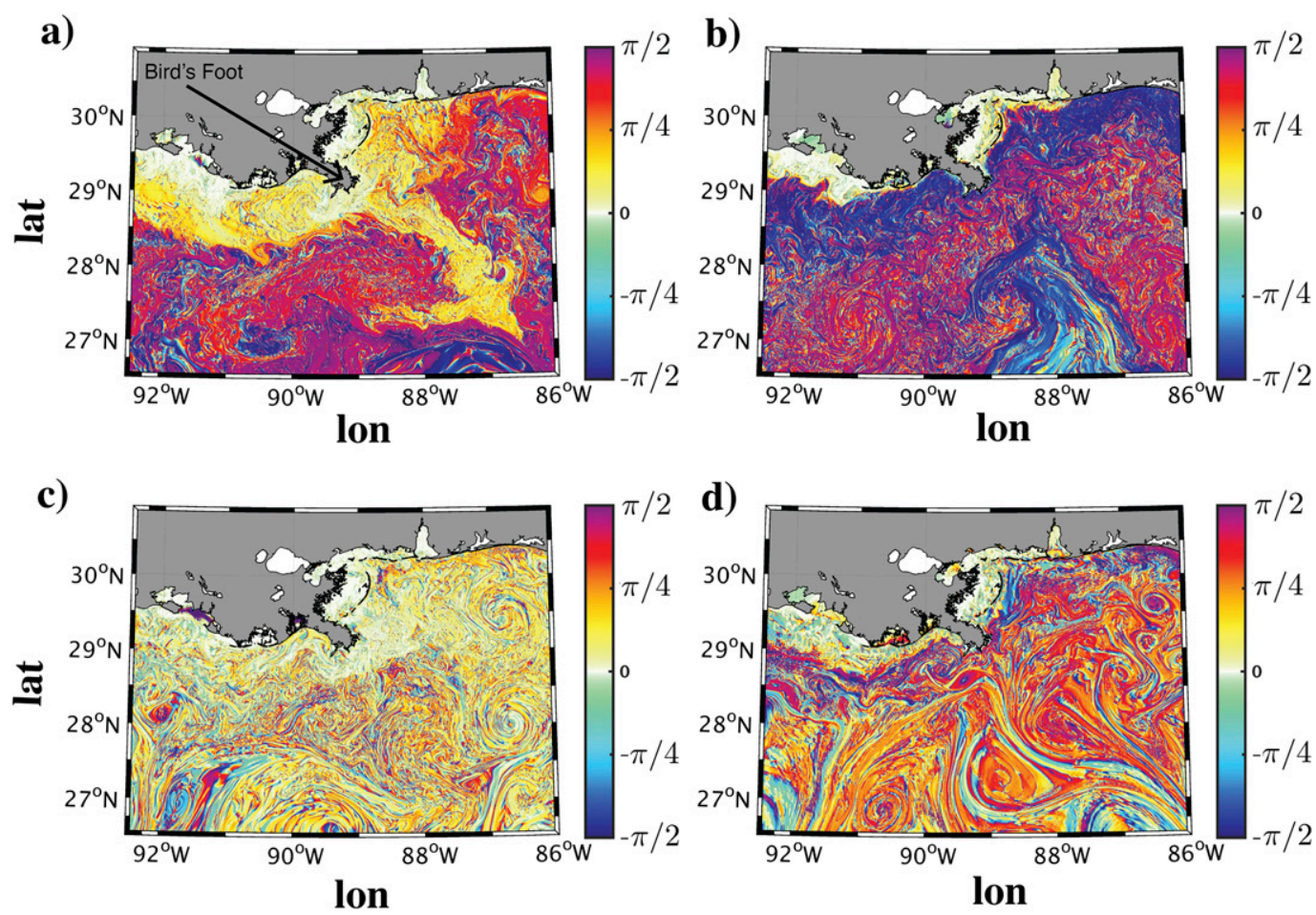

FIG. 2. A snapshot of $\mathrm{Tu}_{x}[(5)]$ at the surface during (a) winter and (c) summer for the With-River solution and during (b) winter and (d) summer for the No-River solution.

only if $\nabla_{h} T$ and $\nabla_{h} S$ are collinear or if one of them is zero, and the relationship between the density ratios and the coordinate-invariant measure of compensation [(3)] is not easily determined. Furthermore, if the dynamics are not statistically steady and are modeled as an initial-value problem where a given surface $\mathrm{T}-\mathrm{S}$ forcing results in both density and spice generation, then the same argument implies that spice will cascade to smaller scales and dissipate faster than density, thereby driving the flow away from compensation.

Representative snapshots of $\mathrm{Tu}_{x}$ during winter and summer for the With-River and No-River solutions are shown in Fig. 2. The spatial maps of $\mathrm{Tu}_{y}$ are very similar (not shown) so that (6) is a good approximation in these solutions. $^{2}$ During winter, the With-River solution shows a clear signature of the Mississippi plume with values between 0 and $\pi / 4$ (Fig. 2a). This indicates that the river outflow is opposing but dominated by salinity gradients. The same is true on the shelf both east and west of the Bird's Foot. Away from the river mouths,

\footnotetext{
${ }^{2}$ In principle, it is possible to diagnose $\theta=\arctan \left[\mathcal{C}_{\mathrm{TS}}\left(\alpha^{2} \nabla_{h} T^{2} / \beta^{2}\right.\right.$ $\left.\nabla_{h} S^{2}\right)$, which is a coordinate-invariant angle that can be interpreted in a similar manner to the Turner angle. In the limit that $\mathrm{Tu}_{x}=\mathrm{Tu}_{y}=\mathrm{Tu}$, the two angles are related via $\tan \theta=2 \tan (\mathrm{Tu}) \sin ^{2}$ (Tu).
}

$\mathrm{Tu}_{x}$ is close to $\pi / 2$, indicating that the density gradients there are temperature dominated. In the No-River solution (Fig. 2b) values are much larger than $\pi / 4$ throughout most of the computational domain, indicating that the density gradients are temperature dominated. The nearly zero $\mathrm{Tu}_{x}$ values very close to shore are associated with the elevated levels of precipitation along the coast (Fig. 3). The reinforcing and temperature-dominated signal near the southern boundary is associated with the Loop Current that brings warmer and fresher waters of Caribbean origin.

During summer, $\mathrm{Tu}_{x}$ in the With-River solution is mainly positive with values between 0 and $\pi / 4$ (Fig. 2c), suggesting that salinity dominates the density gradients in this season. This results from the river outflows being at their maximum. In the No-River solution, density gradients are mainly dominated by temperature, except for a narrow region very close to the shelf, where precipitation contributes freshwater anomalies (Fig. 3), and for the edges of the mesoscale structures that are compensated.

The PDFs of $\mathrm{Tu}_{x}$ during winter and summer are shown in Fig. 4. We distinguish between shelf regions, defined as shallower than $150 \mathrm{~m}$, and offshore regions, defined as deeper than $500 \mathrm{~m}$. The PDFs of $\mathrm{Tu}_{y}$ are nearly identical (not shown), which further supports the validity of the approximation [(6)] in our solutions. None of the PDFs, except for the offshore No-River 

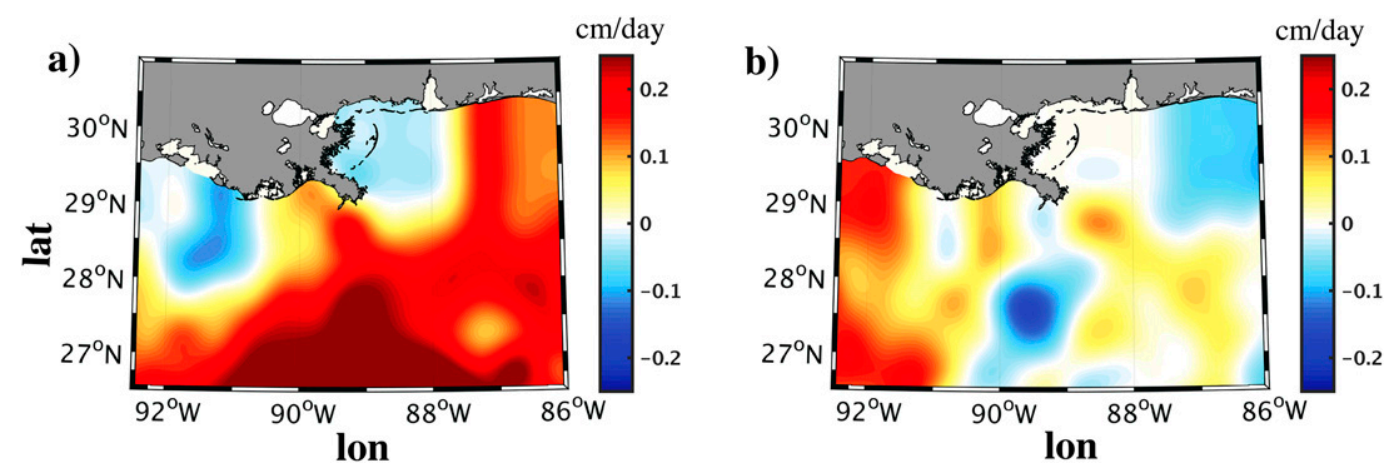

FIG. 3. Climatological HOAPS (Andersson et al. 2010) monthly mean surface freshwater flux $(E-P)$ in (a) January and (b) September, the months corresponding to the winter and summer $\mathrm{Tu}_{x}$ snapshots, respectively, in Fig. 2.

solution during summer, have a peak near $\pi / 4$, suggesting that the northern GoM does not exhibit the more commonly observed compensated signal in the mixed layer. In winter the PDF shapes offshore support a clear temperature-dominated signal independent of the riverine forcing and resemble the one measured by Rudnick and Martin (2002) for a subpolar front in the western northern Atlantic in April. In the remaining panels, the PDFs in the With-River and No-River solutions differ, highlighting that the rivers govern the $T-S$ distribution in the northern GoM.

During winter, on the shelf, the With-River PDF exhibits a weaker temperature-dominated signal, compared to the offshore one, together with a salinitydominated and opposing peak that is associated with the riverine forcing. In the No-River solution, the temperaturedominated peaks are much more pronounced, illustrating that the warmer offshore water (Fig. 4, offshore winter panel) can reach all the way to the shelf in the absence of river outflow. The salinity-dominated peak is more symmetric and concentrated around $\mathrm{Tu}_{x}=0$, compared with the With-River PDF, and is associated with nearshore precipitation patterns (Fig. 3).

During summer, the differences between the offshore PDFs in the No-River and With-River solutions are quite striking. In the With-River solution, the signal is mainly opposing and salinity dominated with most of the values between 0 and $\pi / 4$. This illustrates the increased influence of the rivers in summer (see also Fig. 2). In the No-River solution, the PDF peak shifts to the compensation value of $+\pi / 4$ with a secondary peak in the opposing and temperature-dominated range. ${ }^{3}$ On the shelf, both

\footnotetext{
${ }^{3}$ We checked the mixed layer $T-S$ diagrams in both seasons and found the isopycnals to be nearly straight, suggesting that cabbeling effects are less important here compared with other regions of the ocean (Thomas and Shakespeare 2015).
}

With-River and No-River PDFs have a clear salinitydominated signal that is wider in the With-River solution, similar to winter. In addition, a temperature-dominated signal is only present in the No-River PDF, suggesting again that temperature-dominated water masses have the potential to reach the shore in the absence of river forcing.

\section{Relating T-S compensation to submesoscale currents}

To more accurately interpret the Turner angles with respect to submesoscale currents, we focus on flow features with temperature and salinity gradients that are strong compared with background values. To this end we compute the conditional PDFs only where $\alpha^{2} \nabla_{h} T^{2}+\beta^{2} \nabla_{h} S^{2}$ values are larger than a tenth of the mean value. This threshold is chosen to be the value in the cumulative distribution function of $\alpha^{2} \nabla_{h} T^{2}+\beta^{2} \nabla_{h} S^{2}$, where the slope flattens out (not shown) and includes approximately $8 \%$ of the domain. These frontal $\mathrm{Tu}_{x}$ PDFs are shown in Fig. 5. The large differences between the With-River and NoRiver solutions in all cases demonstrate the significant role of rivers in governing the surface submesoscale flow in the northern GoM during both summer and winter.

In winter, the conditional PDFs of the With-River and No-River solutions are considerably different offshore, while they were nearly identical when computed over the entire domain (Fig. 4, offshore winter). This illustrates the care that must be practiced when interpreting Turner angle PDFs with respect to submesoscale currents. In the No-River solution, the temperaturedominated signal remains, implying that it is indeed a frontal signal. In the With-River solution, however, the peak at $-\pi / 2$ is substantially reduced, whereas a new peak emerges in the salinity-dominated and opposing range that is associated with the freshwater river fronts. On the shelf, the changes to the No-River frontal PDF are again minor compared with the PDF of the entire region (Fig. 4, shelf winter), whereas for the With-River solution the temperature-dominated peaks 


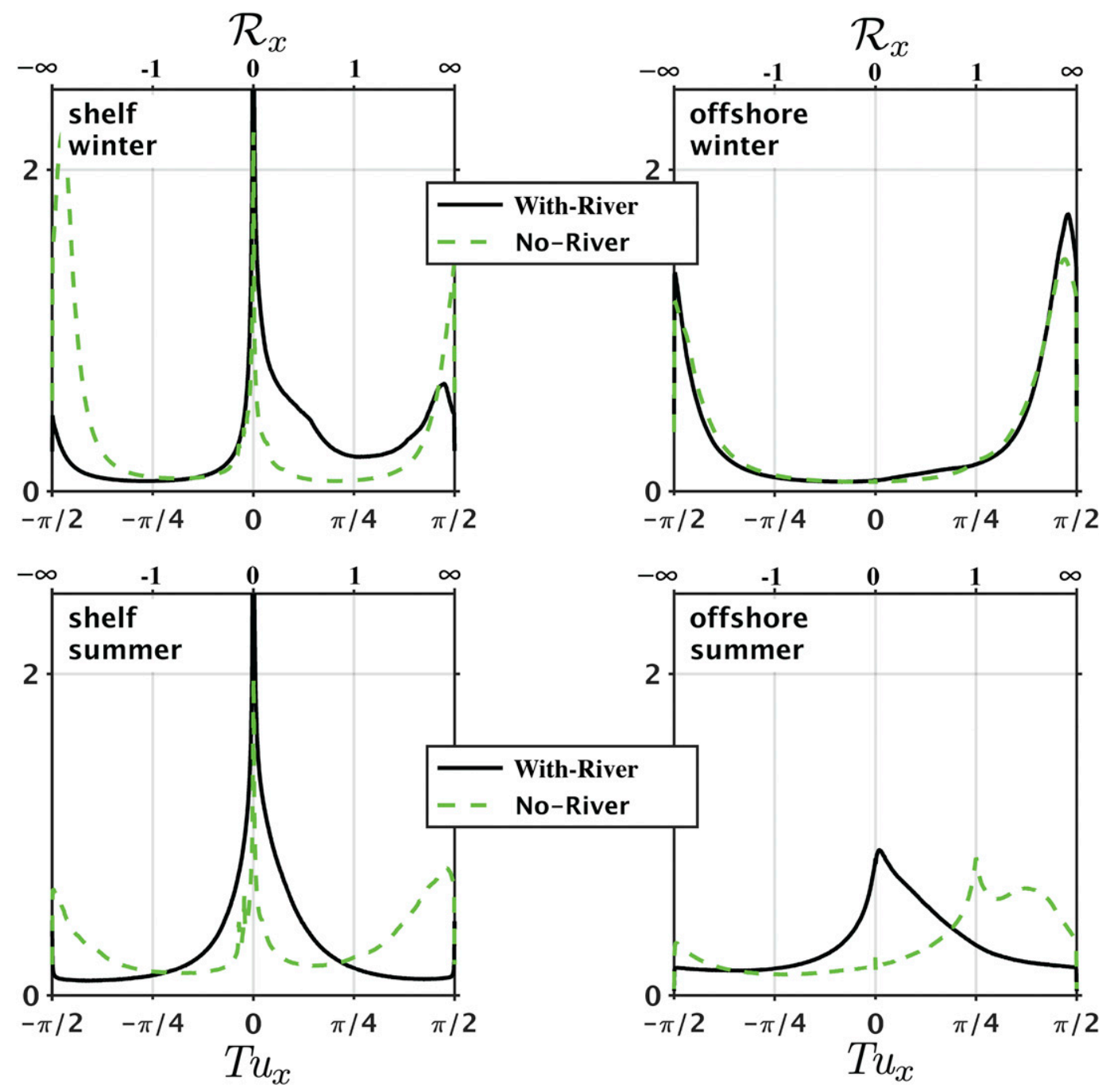

FIG. 4. PDFs of $\mathrm{Tu}_{x}[(5)]$. Shelf regions are defined as shallower than $150 \mathrm{~m}$, and offshore regions are defined as deeper than $500 \mathrm{~m}$.

are completely eliminated. This illustrates that the rivers prevent the offshore, temperature-dominated water masses from reaching the shelf at the surface.

In summer, the With-River solution has very similar frontal PDFs on the shelf and offshore, although the distribution is less symmetric offshore and is skewed toward the opposing range. Furthermore, the temperaturedominated tails seen in the general PDFs during summer (Fig. 4, bottom panels) are now completely missing. In the No-River solution, the perfectly compensated signal at $+\pi / 4$ offshore as well as the temperature-dominated one are more pronounced in the frontal PDFs. This compensated signal corresponds to the edges of the mesoscale structures shown in Fig. 2d. On the shelf, the temperaturedominated peaks are reduced compared with the general PDFs, and the peak around zero is wider and quite similar to the With-River one, suggesting that it is largely dominated by evaporation minus precipitation $(E-P)$ forcing.

A crucial assumption of the physical model describing how compensation arises in the mixed layer (section 3 ) is that the horizontal eddy diffusivity scales nonlinearly with the horizontal buoyancy gradient (Ferrari and Young 1997). Under this assumption, the eddy diffusivity in locations where the spice gradient is much larger (or smaller) than the buoyancy gradient will tend to dissipate buoyancy much faster than spice and consequently align temperature and salinity gradients, thereby leading to compensation (Ferrari and Paparella 2003). This suggests that in regions with large positive $T-S$ covariance $\mathcal{C}_{T S}[(4)]$, the coordinate-invariant measure of the density to spice gradient ratio [(3)], should indicate where a compensation process may take place. 


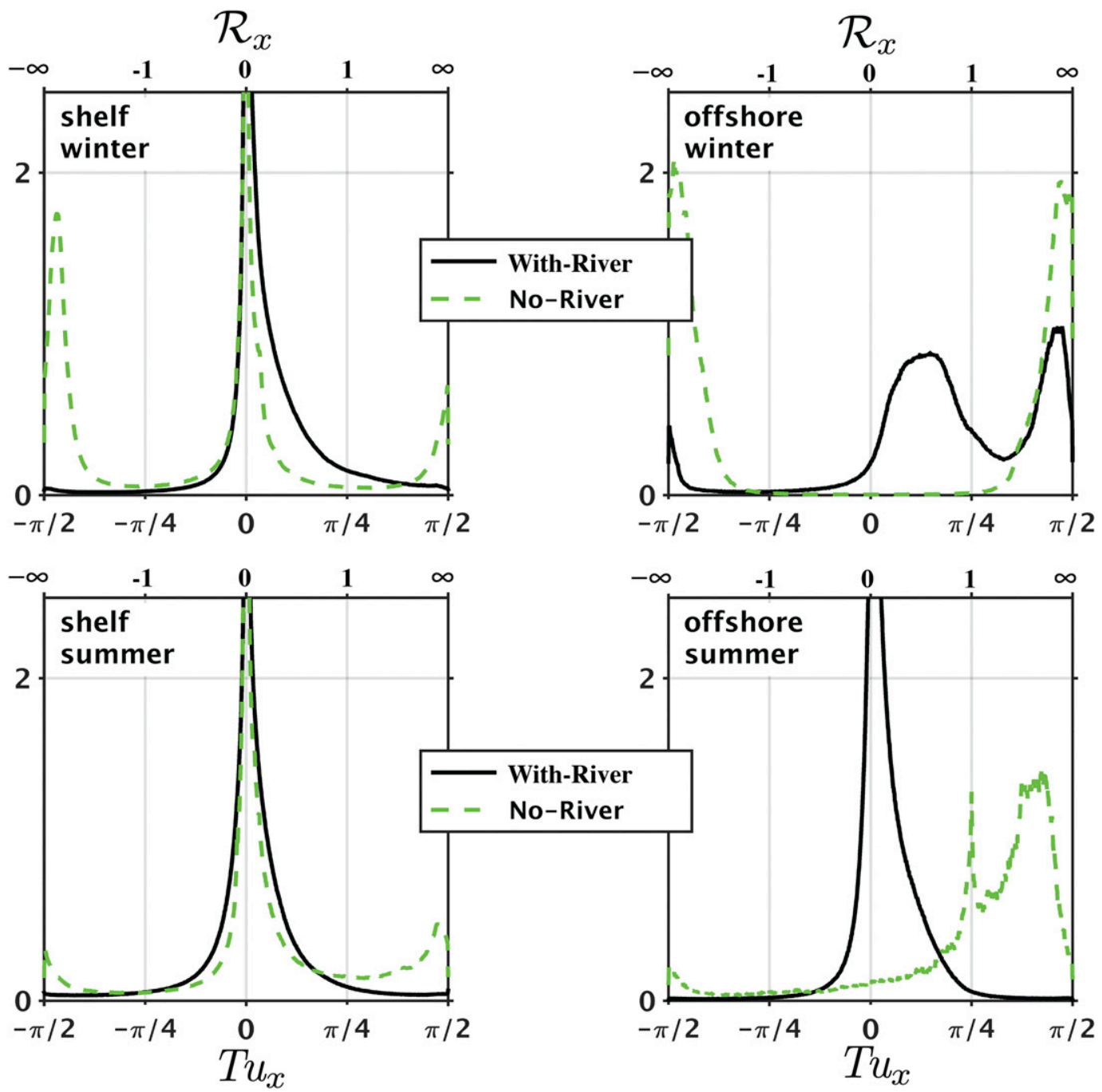

FIG. 5. Conditional PDFs of $\mathrm{Tu}_{x}[(5)]$ computed in flow regions where $\alpha^{2} \nabla_{h} T^{2}+\beta^{2} \nabla_{h} S^{2}$ is larger than a tenth of the mean (see section 3 for detail). Shelf regions are defined as shallower than $150 \mathrm{~m}$, and offshore regions are defined as deeper than $500 \mathrm{~m}$.

To account for the role of submesoscale currents in the compensation process we aim to relate the exchange between APE and eddy kinetic energy (EKE) $\overline{w^{\prime} b^{\prime}}$ with $T-S$ relation measures. Above, $w$ denotes the vertical velocity, $b$ denotes the buoyancy, and primes denote perturbations from a seasonal mean, which is denoted by an overbar. As discussed in Fox-Kemper et al. (2008) and McWilliams (2016), the generation of submesoscale currents is synonymous with an APE to EKE conversion, and $\overline{w^{\prime} b^{\prime}}$ is expected to be positive. In section 7 of Part I [(2a)-(2c)], it was shown that the APE to EKE conversion scales with the square of lateral buoyancy gradient magnitude, irrespective of the submesoscalegenerating process. Any APE release will result in the slumping of isopycnals as well as of isospices, and we assume that such slumping processes will ultimately result in the destruction of lateral buoyancy and spice gradients via the commonly assumed nonlinear diffusion parameterization. Consequently, for an APE reservoir associated with a given buoyancy gradient $\left|\nabla_{h} b\right|$, the amount of APE release $\left.\overline{w^{\prime} b^{\prime}}\right|_{\text {comp }}$ that destroys buoyancy gradients while leaving spice gradients untouched, thereby driving toward compensation, should scale like

$$
\left.\overline{w^{\prime} b^{\prime}}\right|_{\text {comp }} \sim|\nabla b|^{2}\left|\mathcal{C}_{T S}\right|
$$

where the other factors that make (7) dimensionally correct depend on the specific submesoscalegenerating mechanism [(2a)-(2c) in Part I]. When $\left|\mathcal{C}_{T S}\right| \rightarrow 0$, density gradients and spice gradients are 


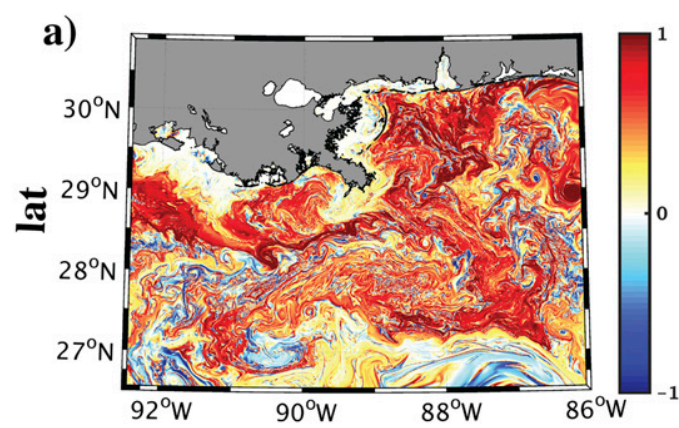

c)

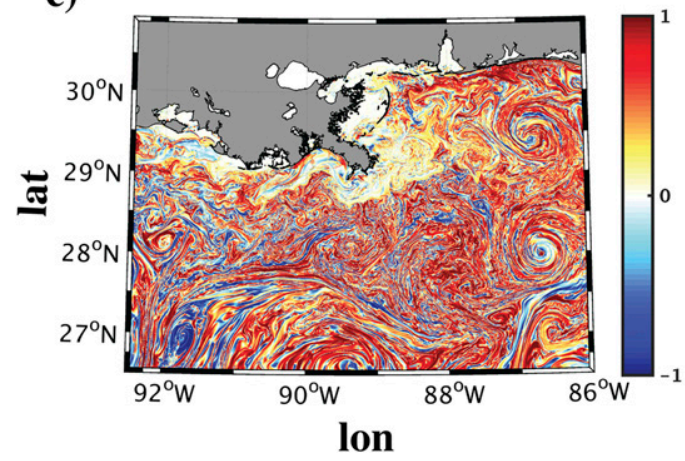

b)

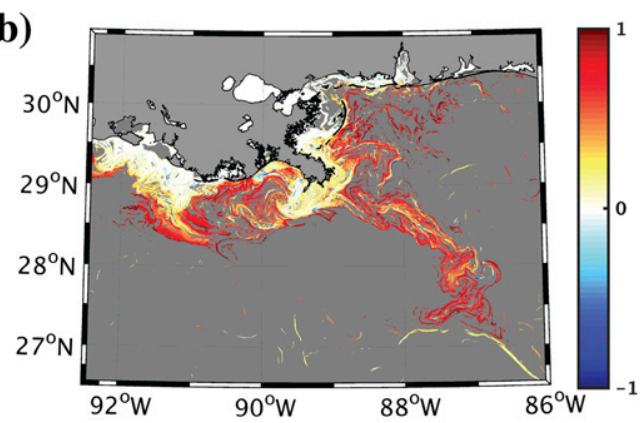

d)

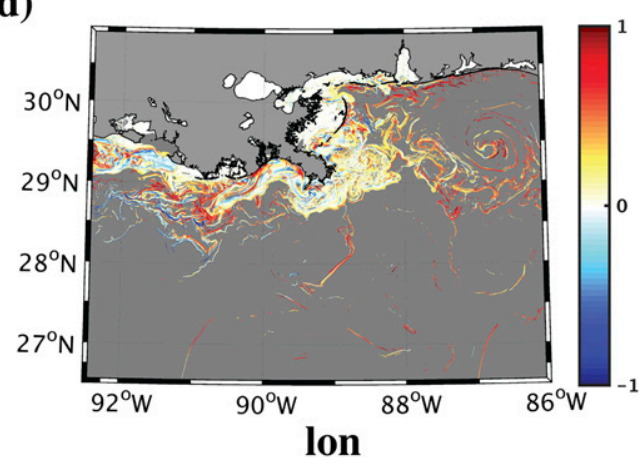

FIG. 6. Representative snapshots of the $T-S$ covariance $\mathcal{C}_{T S}$ [(4)] in (a) winter and (c) summer for the With-River solution. (b), (d) As in (a) and (c), but computed in flow regions where $\alpha^{2} \nabla_{h} T^{2}+\beta^{2} \nabla_{h} S^{2}$ is larger than a tenth of the mean (gray area is masked by the selection criterion).

approximately equal, and the release of APE will lead to the destruction of the same amount of spice and buoyancy, and no compensation can result. Conversely, in the limit that $\left|\mathcal{C}_{T S}\right| \rightarrow 1$, all of the APE stored in $\left|\nabla_{h} b\right|^{2}$ will lead to the destruction of buoyancy gradients, while leaving spice gradients untouched, and the flow will become compensated.

To investigate this argument in our solutions, representative snapshots of the T-S covariance $\mathcal{C}_{T S}$ are shown in Fig. 6. Figures $6 a$ and $6 \mathrm{c}$ show the covariance everywhere in the computational domain, whereas Figs. $6 \mathrm{~b}$ and $6 \mathrm{~d}$ highlight the submesoscale-dominated regions where $\alpha^{2} \nabla_{h} T^{2}+\beta^{2} \nabla_{h} S^{2}$ values are again larger than a tenth of the mean value. In both seasons, much of the domain has very weak gradients and therefore cannot be directly interpreted with respect to submesoscale currents. Regions of significant temperature and salinity gradients are found near the shelf in the vicinity of the rivers' sources and offshore in fronts and filaments. In both seasons most of the strong gradients are opposing at various degrees, although there are some reinforcing regions on the shelf, especially during summer. Large and positive $\mathcal{C}_{T S}$ values are found in the Mississippi River jet region during winter, implying that a submesoscale-induced compensation process may be important there.
To test this hypothesis we compute a Hovmöller diagram of the $\mathrm{Tu}_{x}$ PDFs during the first 18 days of February in the With-River solution offshore (Fig. 7). To focus on submesoscale structures, we only account for flow regions where $\alpha^{2} \nabla_{h} T^{2}+\beta^{2} \nabla_{h} S^{2}$ is larger than a tenth of the spatial mean at every output time. Overall, a persistent temperature-dominated signal, associated with the offshore temperature-dominated fronts, is found, as shown in Fig. 8 (top). In addition, there is a clear tendency toward an opposing signal, in agreement with the seasonalaveraged frontal PDF (Fig. 5, offshore winter). A diurnal cycle in the PDFs around $\mathrm{Tu}_{x} \approx-\pi / 2$ is also visible; however, its analysis is deferred to a future study. Most interestingly, we note an evolution in the PDFs from a salinity-dominated signal around day 6 toward a nearly compensated signal around day 9. This evolution toward compensation corresponds to offshore advection of the river-forced, salinity-dominated gradients that are stirred and mixed with the surrounding Loop Current temperature-dominated gradients (Fig. 8, top). In addition, the APE stored in the salinity-dominated fronts is gradually being released (positive $w b$ in Fig. 8, bottom), consistent with submesoscale restratification processes.

To further examine this process we interpolate the Eulerian $\mathrm{Tu}_{x}$ values onto Lagrangian particles that are 


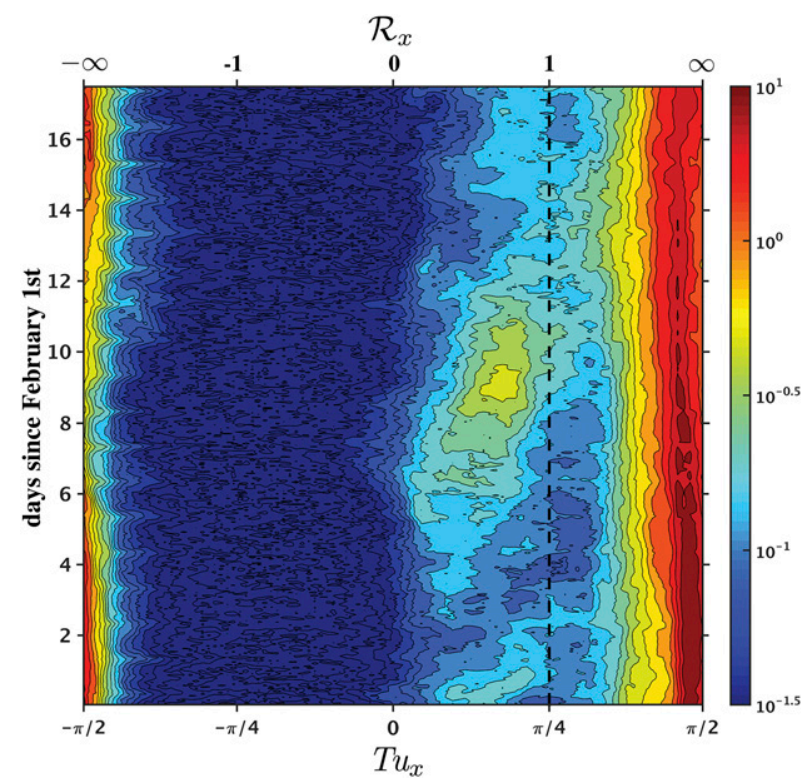

FIG. 7. Hovmöller diagram of $\mathrm{Tu}_{x}$ and $\mathcal{R}_{x}[(5)]$ PDFs in log scale, computed in flow regions where $\alpha^{2} \nabla_{h} T^{2}+\beta^{2} \nabla_{h} S^{2}$ is larger than a tenth of the spatial mean and in water deeper than $500 \mathrm{~m}$ (i.e., offshore) for the With-River solution.

released near the Mississippi River mouth. This allows us to better track the Turner angle evolution of the river water during its offshore advection. The Hovmöller diagrams as a function of time and distance from the particle release location (Figs. 9a,b) illustrate more clearly the gradual evolution toward compensation seen in Fig. 7. When the PDFs are averaged over 2 days and $100 \mathrm{~km}$ (Figs. 9c,d), we note an evolution from a unimodal, salinity-dominated distribution at early times and short distances from the source, toward a bimodal, temperature-dominated and nearly compensated distribution at later times and longer distances from the source. The maintenance of a nearly compensated signal in the Lagrangian Turner angle PDFs is consistent with the argument proposed by previous authors (Ferrari and Young 1997) and implies that the continuous release of APE (Fig. 8, bottom) and subsequent lateral diffusion destroy buoyancy gradients more effectively than spice gradients. The evolution toward a temperaturedominated peak illustrates a lateral mixing of advected river waters that gradually reduces salinity gradients.

\section{Cross-shelf transport mechanisms of fresh river water in winter}

In this section, we investigate in detail the cross-shelf transport of riverine waters during winter, the period of the LASER experiment. In this season, a fast moving, well-defined plume or jet of freshwater forms in the With-River solution (see the opposing and salinitydominated peak in Figs. 7 and 8 and the salinity gradient animation available in the supplemental information
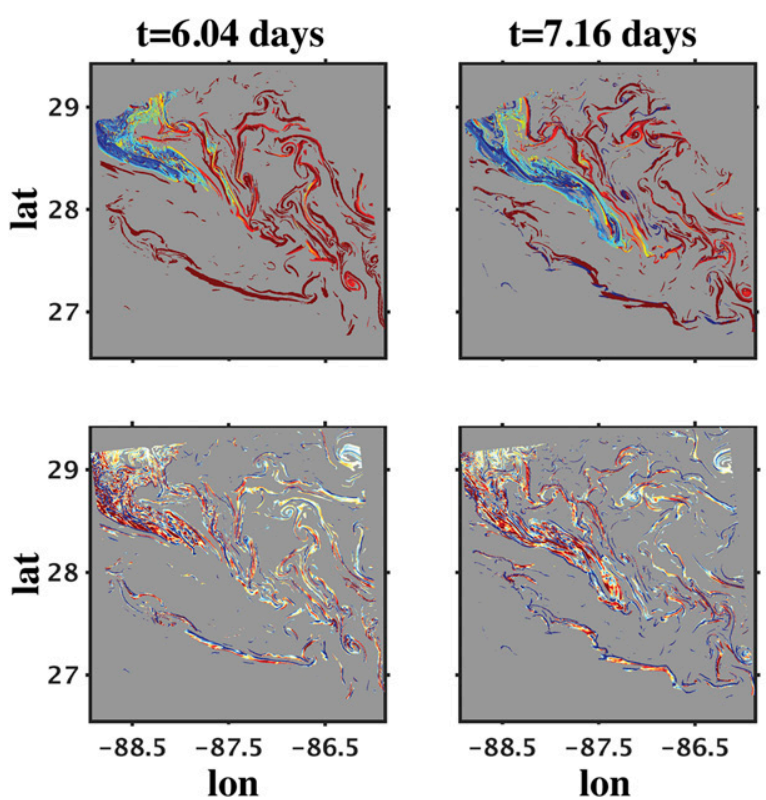
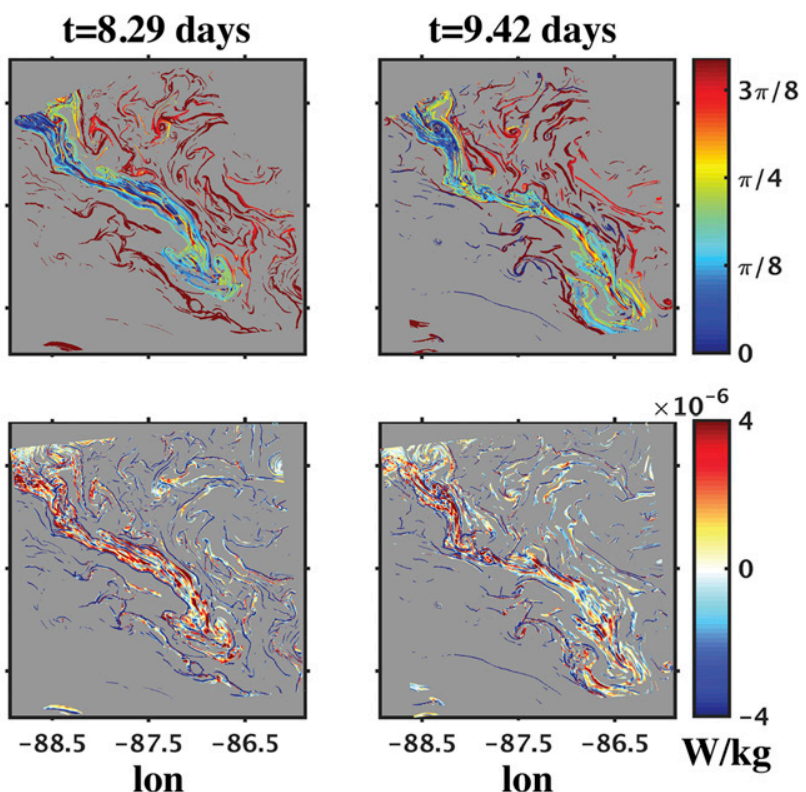

FIG. 8. Snapshots of (top) $\mathrm{Tu}_{x}$ and (bottom) $w b$ at four times relative to $1 \mathrm{Feb}$ in the With-River solution, which corresponds to the evolving nearly compensated peak in Fig. 7. The river water, which is salinity dominated when (top left) entering the domain, gradually evolves toward compensation as it is (top right) advected offshore. The corresponding $w b$ signal is (bottom left) positive and strongest at earliest time and (bottom right) gradually decreases with time. 

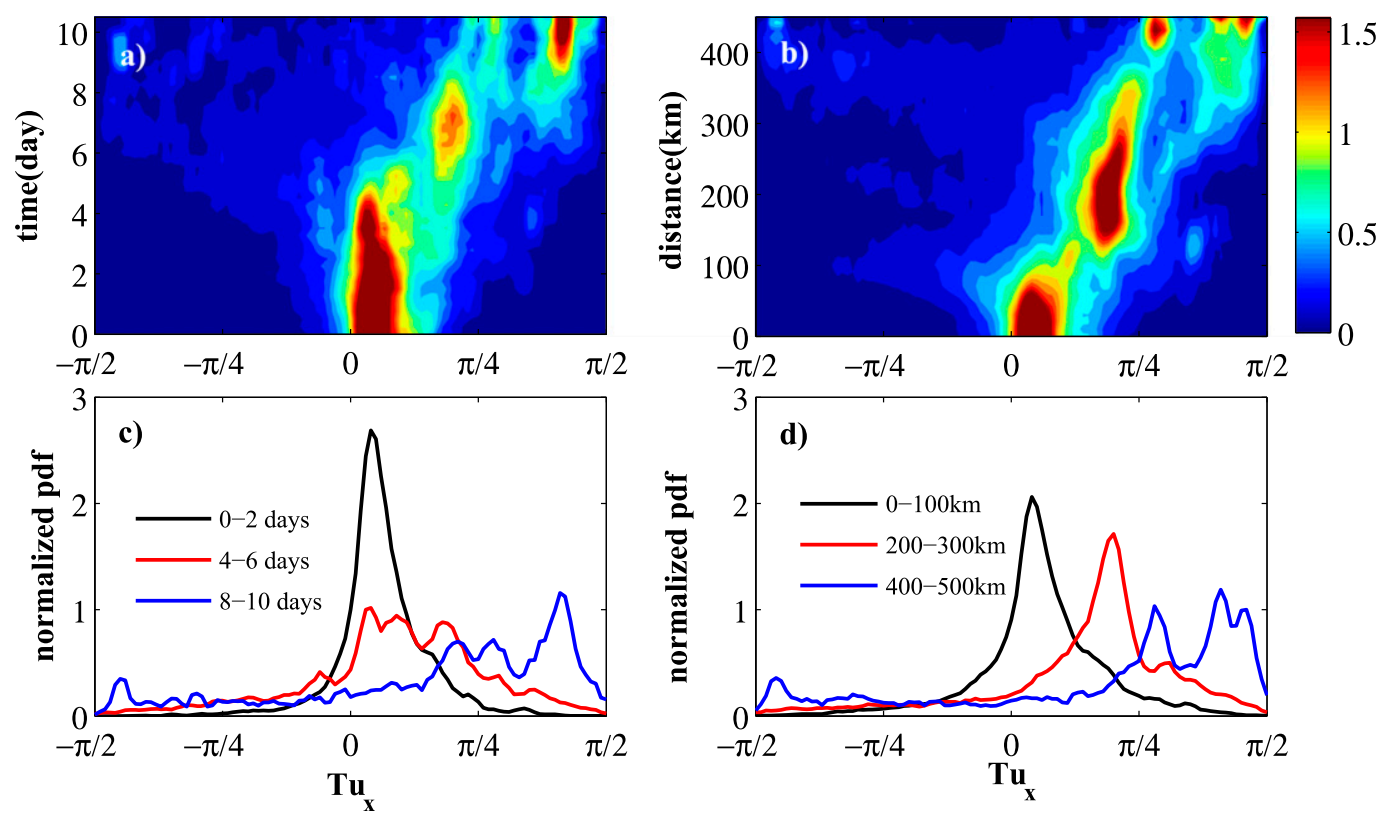

FIG. 9. Hovmöller diagram of $\mathrm{Tu}_{x}$ PDFs, interpolated onto Lagrangian particles, as a function of (a) time and (b) distance from the release location (red circle in Fig. 11). (c),(d) A subsample of the PDFs shown in (a) and (b) using a 2-day average in time and a 100-km average in space.

as animation 1). Such a jet is typically oriented in the northwest-southeast direction and at times can reach across the entire computational domain, in agreement with observations by $\mathrm{Hu}$ et al. (2005). We propose mechanistic models that approximate this cross-shelf transport, distinguishing between the region to the west of the Bird's Foot and the Mississippi River jet.

In summer, the jet pattern is not as well defined and does not reach as far offshore in our simulations. In general, the dynamics of the Mississippi River jet and its offshore extent depend on local winds and the location of the Loop Current eddies (Schiller et al. 2011) and do not exhibit a clear correlation with a specific season. This suggests that the lack of a far-extending plume in our solutions during summer represents a specific numerical realization and that the jet-driven projectile-like ballistic process described below (section $4 \mathrm{~b}$ ) is not confined to the winter months only. In any event, the horizontal resolution of our $500-\mathrm{m}$ solutions allows us to adequately represent shelf dynamics during winter only (see section 4 of Part I for details). Finer resolution than used here is required to resolve in detailed cross-shelf transport processes in summer when the mixed layer depth is shallow. The corresponding analysis is therefore not attempted.

\section{a. West of the Bird's Foot: A diffusive process}

The winter-mean salinity contours west of the Bird's Foot (Fig. 10a) suggest that the cross-shelf transport mechanism there may obey a diffusive process. To verify it, we compute the winter-mean, cross-gradient surface salinity diffusivity

$$
\mathcal{K}_{s}=-\frac{\overline{\mathbf{u}_{h}^{\prime} S^{\prime}} \cdot \nabla_{h} \bar{S}}{\left|\nabla_{h} \bar{S}\right|^{2}},
$$

where u denotes the velocity vector, the $h$ subscript denotes horizontal vector components, $S$ is the sea surface salinity, and primes denote perturbation from the winter mean, which is denoted by a bar. Indeed, we find that $\mathcal{K}_{s}$ values west of the Bird's Foot are generally positive (Fig. 10b) with alongshore average values of about $200 \mathrm{~m}^{2} \mathrm{~s}^{-1}$ (Fig. 10d) that are coherent over roughly $110 \mathrm{~km}$ in the offshore direction. This confirms that the cross-shelf river water transport west of the Bird's Foot can be adequately described by a diffusive process, and the cross-shelf diffusive time scale for a freshwater parcel to get transported offshore a distance $L=100 \mathrm{~km}$ is $t_{\text {diff }}=L^{2} / \mathcal{K}_{s} \sim 578$ days.

\section{b. The Mississippi River jet: A ballistic process}

The distinct river jet signature in the salinity contours east of the Bird's Foot (Fig. 10a) and the generally negative $\mathcal{K}_{s}$ values there (Fig. 10b) imply that the crossshelf freshwater transport mechanism within the jet is not diffusive. We test whether it obeys a ballistic process (i.e., with a projectile-like transport) by deploying a cluster of 5019 particles daily between 2 and 9 February 
a)

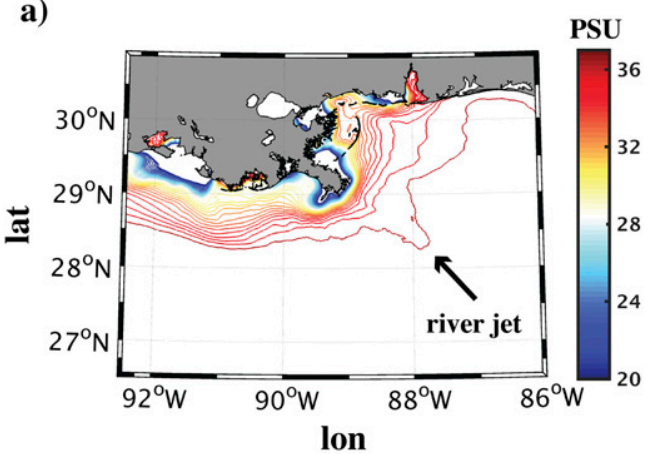

c)

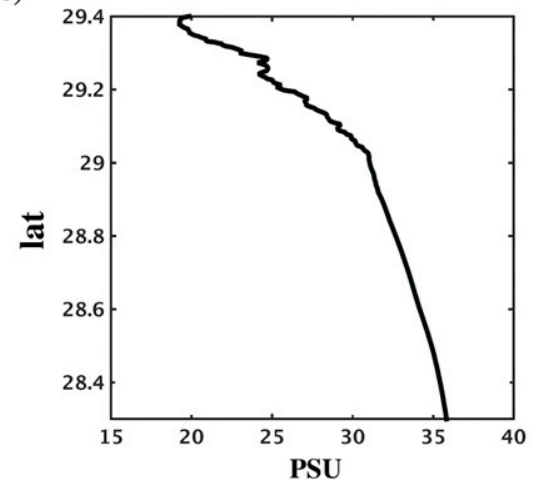

b)

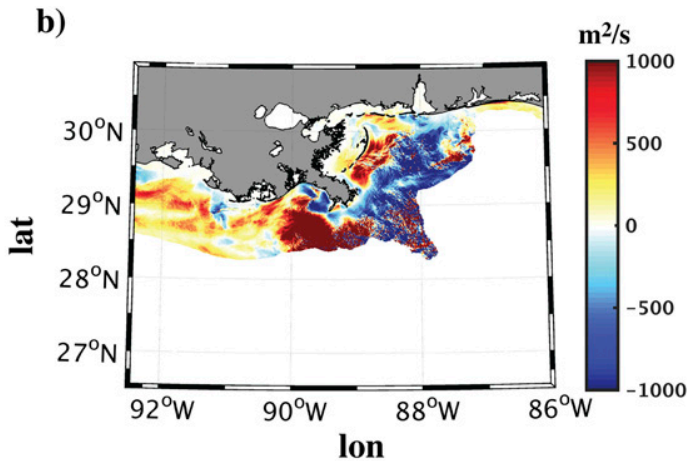

d)

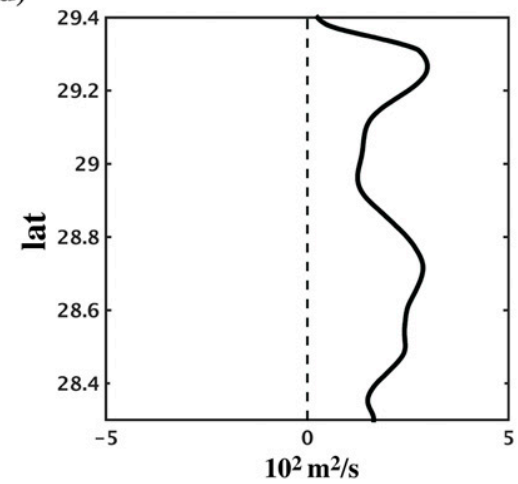

FIG. 10. (a) Winter-mean salinity in the With-River solution and (b) the corresponding cross-gradient salinity diffusivity $\mathcal{K}_{s}[(8)]$. (c) The alongshore-averaged salinity and (d) alongshore-averaged $\mathcal{K}_{s}$, west of the Bird's Foot. Alongshore averages were computed between longitudes $93^{\circ}$ and $89.85^{\circ} \mathrm{W}$.

close to the Mississippi River mouth (Fig. 11) at a time when the river jet is active and extending far offshore. In the analysis that follows, sea surface temperature, salinity, and density along with the corresponding gradient magnitudes at particle locations are the interpolated Eulerian values. To focus on the particles that follow the river jet, we only compute statistics on those with an initial salinity gradient magnitude larger than $10^{-3} \mathrm{psu} \mathrm{m}^{-1}$ and that reach the area south of latitude $26.8^{\circ}$ and west of longitude $-87^{\circ}$. On average $3.4 \%$ of the particles satisfy these constraints (white dots in Fig. 11 indicate their daily mean position). The Lagrangian-averaged surface quantities, as a function of time and distance from the source, are shown in Figs. 12 and 13, respectively. As expected, both temperature and salinity values increase with time and distance as the particles are advected offshore by the river jet. In addition, salinity and temperature gradient magnitudes decrease with time and distance, following the river jet. There is a local increase in temperature gradients roughly $150 \mathrm{~km}$ south of the source; however, the density and density gradient magnitudes are largely salinity dominated (right panels in Figs. 12 and 13), implying that salinity and salinity gradients are the best indicators for the river water, in agreement with the $T-S$ analysis of section 3. The $e$-folding time and length scales for $\left|\nabla_{h} S\right|$ and $\left|\nabla_{h} \rho\right|$ indicate that the cross-shelf ballistic time $t_{\text {ballis }}$ for a freshwater parcel to get transported $\sim 100 \mathrm{~km}$

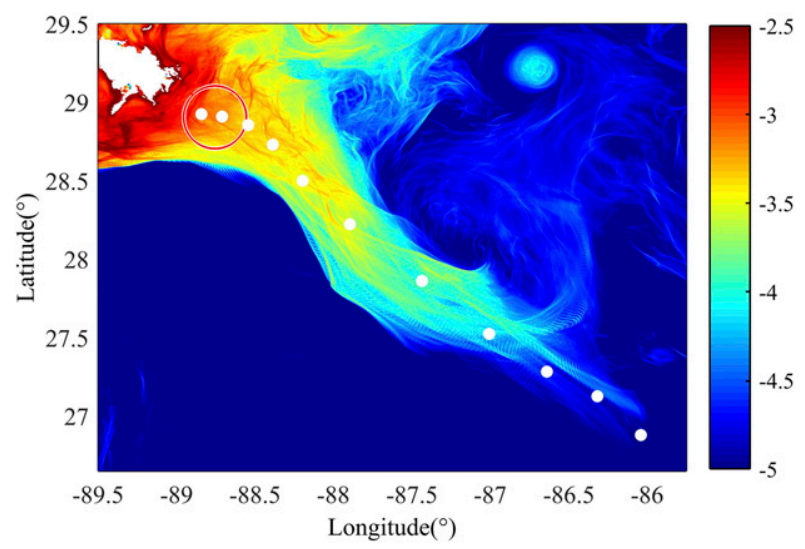

FIG. 11. Salinity gradient magnitude $\left|\nabla_{h} S\right|$ in log scale, time averaged over the Lagrangian release period (1 to $10 \mathrm{Feb}$ ). Red circle indicates the release location of 5019 particles, which was repeated once per day during the Lagrangian release period. White dots indicate the daily mean location of the particles that were used for the analysis in Figs. 12 and 13 (see section 4b for detail). 

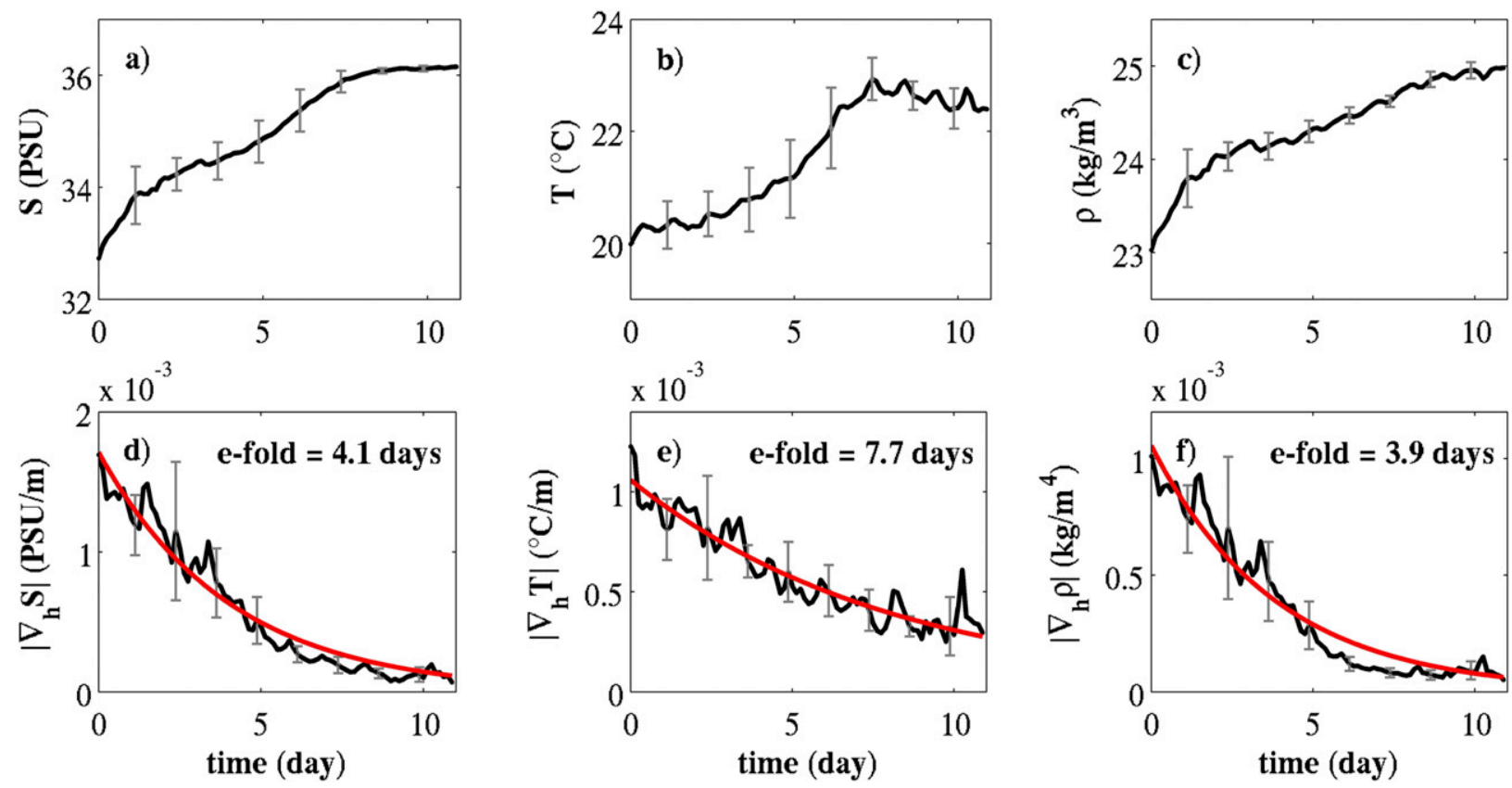

FIG. 12. (a) Salinity $S$, (b) potential temperature $T$, and (c) potential density $\rho$ averaged on particles as function of time (denoted by white dots in Fig. 11). (d)-(f) Gradient magnitudes of the fields in the top panels. Error bars indicate one standard deviation over eight particle deployments. Solid red line indicates the exponential fit to the data (solid black). Text inset indicates the corresponding $e$-folding scale.

offshore would be approximately 4 days, which is two orders of magnitudes smaller than the estimated diffusive time $t_{\text {diff }}$ to the west (section 4a). Our analysis focuses on a time frame over which the river jet is particularly active, and the Lagrangian statistics emphasize particles that are advected by the jet. As a result, we expect the estimated $t_{\text {ballis }}$ to be a lower bound. Nevertheless, we argue that the transport east of the Bird's Foot will often be dominated by a ballistic process that is substantially more efficient than the diffusive one at play to the west.

\section{Summary}

Realistic, submesoscale-resolving, numerical simulations are used to investigate submesoscale dynamics in the northern Gulf of Mexico (GoM), the location of the 2010 Deepwater Horizon oil spill as well as the GLAD and LASER field experiments. In Part I, we examined how the Mississippi-Atchafalaya River system (rivers) impacts submesoscale currents, analyzing two solutions with (With-River) and without (No-River) river forcing at two horizontal resolutions: 500 and $1500 \mathrm{~m}$. We found that both river forcing and mesoscale variability impact the generation of submesoscale circulations in the northern GoM during winter and summer. Here, the second of three companion papers, we analyze the temperature-salinity $(T-S)$ relations and cross-shelf freshwater transport focusing on the 500-m horizontal resolution set to provide an alternative quantification for the effects of the rivers in governing the dynamics in this region. In support of Part I, we find that river forcing has a key role in determining $T-S$ distributions and in governing cross-shelf transport processes in the northern GoM.

First, we examine Turner angle statistics [(3)] in both simulations and show that the surface PDFs do not exhibit the commonly observed mixed layer compensated peak near $+\pi / 4$ (Rudnick and Martin 2002). During winter, the With-River solution has a nearshore, salinity-dominated signal, which is associated with the river waters, and an offshore, temperature-dominated signal, which is associated with Loop Current waters. In the absence of river forcing, the surface, nearshore, salinity-dominated signal is reduced, and the offshore, temperature-dominated signal can reach closer to shore. In summer, the With-River solution is characterized by a salinity-dominated peak both nearshore and offshore that is associated with the increased river influence. In the No-River solution, both a compensated peak and a temperature-dominated peak are found offshore. The compensated signal is observed at the edges of larger mesoscale structures, and the temperature-dominated signal is associated with the fronts and filaments that, similar to winter, are able to propagate closer to shore. 

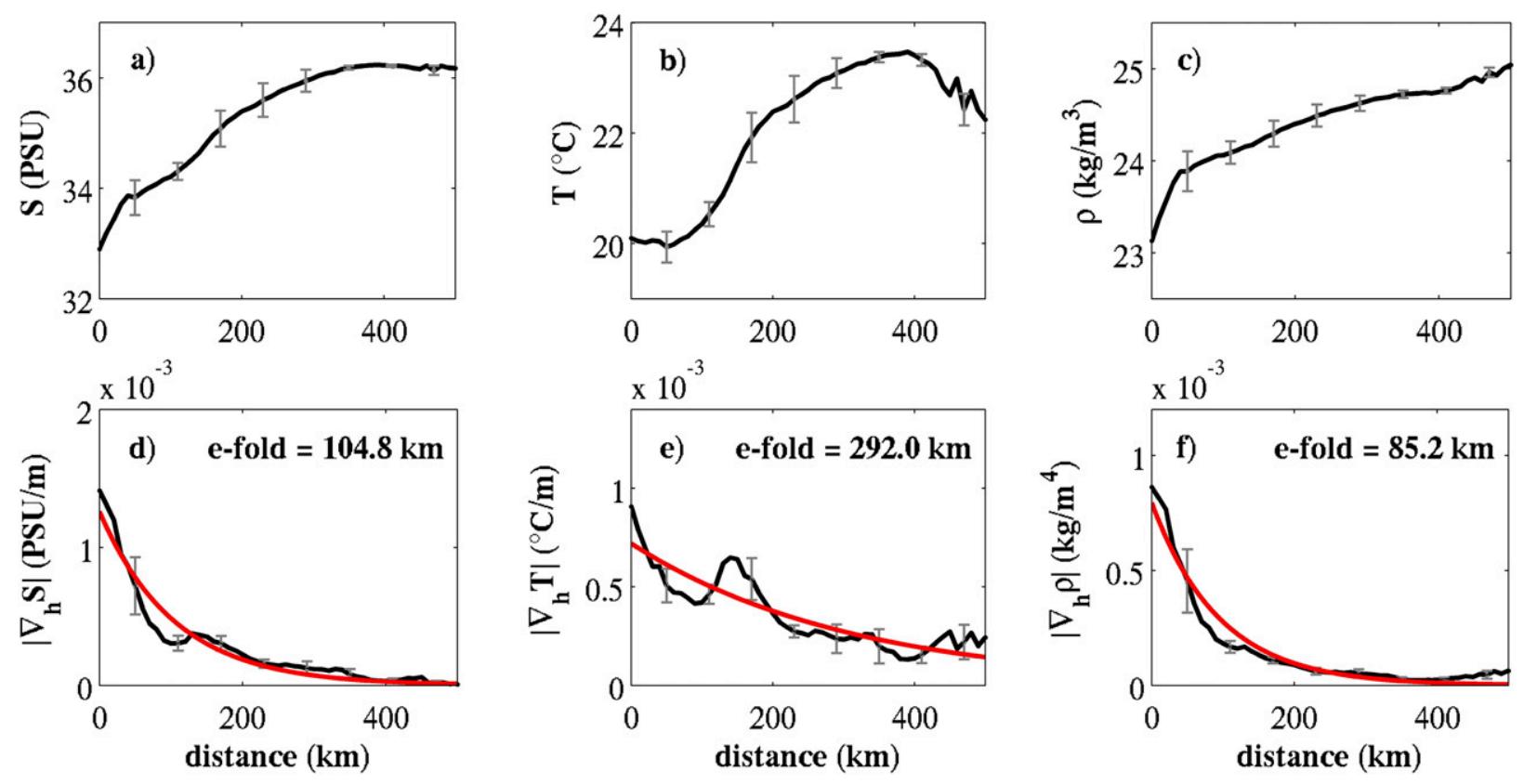

FIG. 13. As in Fig. 12, but computed as a function of distance from the release site (red circle in Fig. 11).

There are substantial differences between With-River and No-River Turner angle PDFs, highlighting the significance of freshwater input in controlling $T-S$ relations in the northern GoM.

To interpret $T-S$ relations with respect to submesoscale currents, we examine conditional Turner angle PDFs in flow regions where temperature and salinity gradients are large relative to their surroundings. The conditional PDFs are found to be quite different than the general ones, emphasizing the care that must be practiced when interpreting Turner angle statistics with respect to submesoscale dynamics. It has been previously suggested (Ferrari and Rudnick 2000) that restratification processes in the mixed layer, which are often linked to submesoscale current generation (Fox-Kemper et al. 2008), together with an assumed horizontal diffusivity that scales nonlinearly with the lateral buoyancy gradient (Ferrari and Young 1997), can explain the commonly observed compensated signal in the ocean mixed layer. By assuming that all of the slumping of isopycnals and isospices during a submesoscale-inducing APE release will result in the destruction of density and spice gradients by such nonlinear diffusion, we are able to propose a scaling estimate [(7)] for the submesoscale-induced compensation that is based on the magnitude of the temperature-salinity covariance $\mathcal{C}_{T S}[(4)]$. In flow regions where $\left|\mathcal{C}_{T S}\right| \rightarrow 1$, the released APE will result in a much faster destruction of buoyancy gradients compared with spice gradients, thereby leading to compensation. On the contrary, in flow regions where $\left|\mathcal{C}_{T S}\right| \rightarrow 0$, the released
APE will result in similar destruction rates of buoyancy and spice gradients, and no compensation is expected to occur. In our solutions covariance values close to 1 are often found in the Mississippi River fronts, and we have indeed shown that as the river water is advected offshore the flow evolves toward compensation in regions of APE release. More work is required to quantify whether specific submesoscale APE release mechanisms, such as frontogenesis (Hoskins and Bretherton 1972), mixed layer eddies (Fox-Kemper et al. 2008), or boundary layer turbulence (Gula et al. 2014; McWilliams et al. 2015), are more efficient in driving the flow toward compensation. Furthermore, the sensitivity of the submesoscale-induced compensation signal to global and local atmospheric forcing, the significance of nonclimatological weather events, and the equilibration time scales are all left for future work.

In winter, the river fronts' evolution toward compensation is accompanied by an additional process that mixes river water, reduces the salinity gradients, and leads to a temperature-dominated signal away from the river mouth. This mixing process is facilitated by a jet of riverine water that often extends far offshore and transports the freshwater to regions were temperature-dominated fronts abound. The occurrence of frequent, far-extending advection of fresh riverine water by the Mississippi jet in winter motivates us to examine whether the cross-shelf freshwater transport mechanisms will differ in the jet and outside of it, west of the Bird's Foot. We found that to the west of the Bird's Foot the cross-shelf transport of river 
water is well modeled by a diffusive process, whereas in the jet it is better represented by a ballistic process. The jet-driven ballistic process is estimated to be substantially more efficient (as much as two orders of magnitudes whenever the jet is well developed) in transporting freshwater offshore.

Acknowledgments. This work was made possible by a grant from the Gulf of Mexico Research Initiative through the CARTHE Consortium. Data are publicly available through the Gulf of Mexico Research Initiative Information and Data Cooperative (GRIIDC) online (at https://data.gulfresearchinitiative.org; https://doi.org/ 10.7266/N7PK0DK2, https://doi.org/10.7266/N7F18X4S, https://doi.org/10.7266/N75H7DQ5, https://doi.org/ 10.7266/N7JS9NVS, https://doi.org/10.7266/N79885FW, and https://doi.org/10.7266/N7CN720V for the Lagrangian data). RB, JCM, and AFS are further supported by ONR N000141410626. The Extreme Science and Engineering Discovery Environment (XSEDE) provided support for computing.

\section{REFERENCES}

Andersson, A., K. Fennig, C. Klepp, S. Bakan, H. Graßl, and J. Schulz, 2010: The Hamburg Ocean Atmosphere Parameters and Fluxes from Satellite Data-HOAPS-3. Earth Syst. Sci. Data, 2, 215-234, doi:10.5194/essd-2-215-2010.

Barkan, R., J. C. McWilliams, A. F. Shchepetkin, M. J. Molemaker, L. Renault, A. Bracco, and J. Choi, 2017: Submesoscale dynamics in the northern Gulf of Mexico. Part I: Regional and seasonal characterization and the role of river outflow. J. Phys. Oceanogr., 47, 2325-2346, https://doi.org/10.1175/JPO-D-17-0035.1.

Choi, J., A. Bracco, R. Barkan, J. C. McWilliams, A. F. Shchepetkin, and M. J. Molemaker, 2017: Submesoscale dynamics in the northern Gulf of Mexico. Part III: Lagrangian implications. J. Phys. Oceanogr., 47, 2361-2376, https://doi.org/ 10.1175/JPO-D-17-0036.1.

Ferrari, R., and W. Young, 1997: On the development of thermohaline correlations as a result of nonlinear diffusive parameterizations. J. Mar. Res., 55, 1069-1101, doi:10.1357/ 0022240973224094.

— upper ocean. J. Geophys. Res., 105, 16 857-16 883, doi:10.1029/ 2000JC900057.

- - , and F. Paparella, 2003: Compensation and alignment of thermohaline gradients in the ocean mixed layer. J. Phys. Oceanogr., 33, 2214-2223, doi:10.1175/ 1520-0485(2003)033<2214:CAAOTG > 2.0.CO;2.

Fox-Kemper, B., R. Ferrari, and R. Hallberg, 2008: Parameterization of mixed layer eddies. Part I: Theory and diagnosis. J. Phys. Oceanogr., 38, 1145-1165, doi:10.1175/2007JPO3792.1.

Gula, J., M. J. Molemaker, and J. C. McWilliams, 2014: Submesoscale cold filaments in the Gulf Stream. J. Phys. Oceanogr., 44, 2617-2643, doi:10.1175/JPO-D-14-0029.1.

Hoskins, B. J., and F. Bretherton, 1972: Atmospheric frontogenesis models: Mathematical formulation and solution. J. Atmos.
Sci., 29, 11-37, doi:10.1175/1520-0469(1972)029<0011: AFMMFA $>2.0 . \mathrm{CO} ; 2$.

Hu, C., J. R. Nelson, E. Johns, Z. Chen, R. H. Weisberg, and F. E. Müller-Karger, 2005: Mississippi River water in the Florida Straits and in the Gulf Stream off Georgia in summer 2004. Geophys. Res. Lett., 32, L14606, https://doi.org/10.1029/ 2005 GL022942.

Large, W., and S. Yeager, 2009: The global climatology of an interannually varying air-sea flux data set. Climate Dyn., 33, 341-364, doi:10.1007/s00382-008-0441-3.

Mason, E., J. Molemaker, A. F. Shchepetkin, F. Colas, J. C. McWilliams, and P. Sangrà, 2010: Procedures for offline grid nesting in regional ocean models. Ocean Modell., 35, 1-15, doi:10.1016/j.ocemod.2010.05.007.

McWilliams, J. C., 2016: Submesoscale currents in the ocean. Proc. Roy. Soc. London, A472, 20160117, https://doi.org/10.1098/ rspa.2016.0117.

_ J. Gula, M. J. Molemaker, L. Renault, and A. F. Shchepetkin, 2015: Filament frontogenesis by boundary layer turbulence. J. Phys. Oceanogr., 45, 1988-2005, doi:10.1175/ JPO-D-14-0211.1.

North, E. W., E. Adams, Z. Z. Schlag, C. R. Sherwood, R. R. He, K. H. K. Hyun, and S. A. Socolofsky, 2011: Simulating oil droplet dispersal from the Deepwater Horizon spill with a Lagrangian approach. Monitoring and Modeling the Deepwater Horizon Oil Spill: A Record-Breaking Enterprise, Geophys. Monogr., Vol. 195, Amer. Geophys. Union, 217-226.

Risien, C. M., and D. B. Chelton, 2008: A global climatology of surface wind and wind stress fields from eight years of QuikSCAT scatterometer data. J. Phys. Oceanogr., 38, 2379-2413, doi:10.1175/2008JPO3881.1.

Ruddick, B., 1983: A practical indicator of the stability of the water column to double-diffusive activity. Deep-Sea Res., 30A, 1105-1107, doi:10.1016/0198-0149(83)90063-8.

Rudnick, D. L., and J. P. Martin, 2002: On the horizontal density ratio in the upper ocean. Dyn. Atmos. Oceans, 36, 3-21, doi:10.1016/S0377-0265(02)00022-2.

Schiller, R., V. H. Kourafalou, P. Hogan, and N. Walker, 2011: The dynamics of the Mississippi River plume: Impact of topography, wind and offshore forcing on the fate of plume waters. J. Geophys. Res., 116, C06029, https://doi.org/10.1029/ 2010JC006883.

Schmitt, R. W., 1981: Form of the temperature-salinity relationship in the central water: Evidence for double-diffusive mixing. J. Phys. Oceanogr., 11, 1015-1026, doi:10.1175/ 1520-0485(1981)011<1015:FOTTSR>2.0.CO;2.

Shchepetkin, A. F., and J. C. McWilliams, 2005: The Regional Oceanic Modeling System: A split-explicit, free-surface, topography-following-coordinate oceanic model. Ocean Modell., 9, 347-404, doi:10.1016/j.ocemod.2004.08.002.

— , and - 2011: Accurate Boussinesq oceanic modeling with a practical, stiffened equation of state. Ocean Modell., 38, 41-70, doi:10.1016/j.ocemod.2011.01.010.

Smith, K. S., and R. Ferrari, 2009: The production and dissipation of compensated thermohaline variance by mesoscale stirring. J. Phys. Oceanogr., 39, 2477-2501, doi:10.1175/ 2009JPO4103.1.

Thomas, L. N., and C. J. Shakespeare, 2015: A new mechanism for mode water formation involving cabbeling and frontogenetic strain at thermohaline fronts. J. Phys. Oceanogr., 45, 2444-2456, doi:10.1175/JPO-D-15-0007.1. 